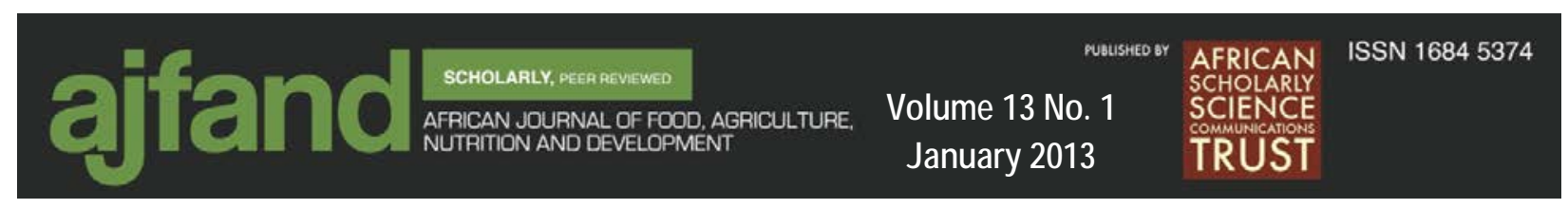

\title{
ADDRESSING CHILDHOOD UNDERNUTRITION IN TANZANIA: CHALLENGES AND OPPORTUNITIES
}

\section{Bundara $\mathrm{N}^{1,2}$, Mwanri $\mathrm{L}^{1 *}$ and $\mathrm{J}$ Masika ${ }^{3}$}

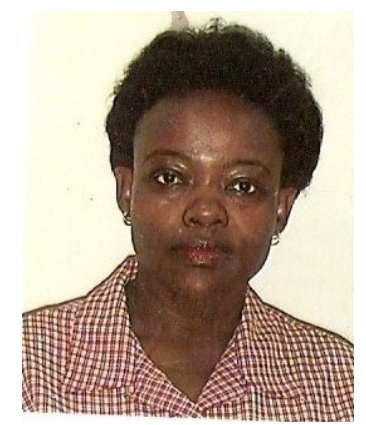

\section{Lillian Mwanri}

*Corresponding author: lillian.mwanri@flinders.edu.au

${ }^{1}$ Discipline of Public Health, School of Medicine, Faculty of Health Sciences,Flinders University.

${ }^{2}$ Department of Food Science and Technology, Sokoine University of Agriculture, Morogoro, Tanzania.

${ }^{3}$ Intercountry Services, Statewide Services Directorate, Families SA, Department for Education and Child Development, Government of South Australia 


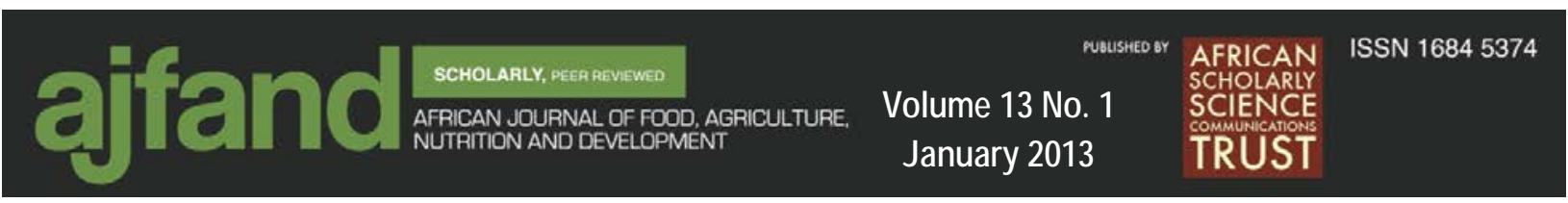

\section{ABSTRACT}

Childhood undernutrition is highly prevalent in low and middle-income countries resulting in a substantial increase in overall disease burden and mortality. The problem is markedly severe in low-income countries particularly in Africa, and Tanzania is not exceptional. Childhood undernutrition is associated with decreased productivity resulting in a vicious cycle of poverty in affected families, communities and nations. Children who survive after two years of life may develop poor health outcomes including faltering growth and irreversible damage to their cognitive, physical and psychosocial development. In a long term, childhood undernutrition can lead to poor socio-economic development of individuals, families and affected communities. Childhood undernutrition in African countries significantly contributes to poor development and the burden of disease as it complicates the existing problem of infectious diseases. Current strategies addressing this problem largely utilise a medical care model which aims to reduce mortality and may have limited selected preventative aspects confined broadly to vaccinations, food fortifications, and micronutrient supplementations. It is apparent that environmental, cultural and social factors-are receiving limited attention. This complex and dire situation demands systematic, effective comprehensive multi-level and multi-sectoral policy drivers that provide effective socioeconomic, environmental, health policies and legislations in the pursuit of effective, equitable and just delivery of social and health services for all groups of its citizens regardless of their socio-economic status. Tanzania as a nation alongside other developing countries need to recognise the magnitude of this scourge and develop comprehensive approaches that will enable development of legislations, policies and long term solution to childhood undernutrition. This paper reviews strategies outside of the health sector with high potential for preventing childhood undernutrition in Tanzania and that can be translated in many developing countries. Comprehensive range of legislations and policies are recommended for implementation of interventions to reduce their occurrence or ameliorate childhood undernutrition consequences.

Key words: childhood undernutrition, Tanzania, effective approach 


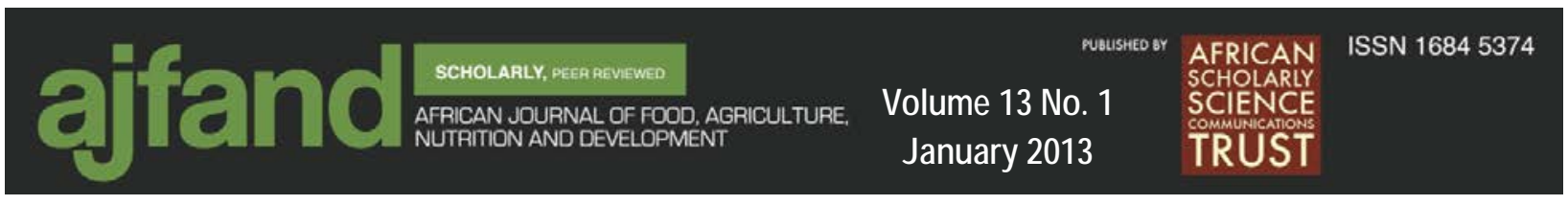

\section{INTRODUCTION}

It is well recognised that childhood undernutrition causes a wide range of health, social and economic problems including poor quality of life, reduction in economic growth and increase in the cost of health care at individual and the government level [1]. As such good nutrition is the cornerstone for survival, health and development.

Childhood undernutrition is one of the major and serious public health challenges in developing countries and the United Nations Children's Fund (UNICEF) reports undernutrition to accounts for over $50 \%$ of childhood mortality worldwide [2-4]. Children below five years of age are the most affected. Undernourished children tend to have lowered resistance to infection and are more likely to die from such common childhood ailments including diarrheal illnesses and respiratory infections.

Childhood undernutrition during the first two years of life has been associated with irreversible harm and is linked to higher rates of morbidity and mortality, impaired cognitive ability and poor school performance in children. Childhood undernutrition has also been associated with decreased productivity and reduction in the effectiveness of labor leading to reduced lifetime earnings for adults, thus contributing to the devastating cycle of starvation and protracted poverty [2]. Children who survive after two years of life may be locked into a vicious cycle of recurring sickness and faltering growth, often with irreversible damage to their cognitive and social development. This decreases the quality of life and life expectancy considerably [2]. It is also a common fact that well-nourished children perform better in school, grow into healthy adults and in turn give their children a better start in life and continue to be healthy adults $[3,5]$.

It is a common knowledge that good nutrition is necessary for a child's development. In most developing countries, childhood undernutrition remains the most serious public health problem and the biggest contributor to child morbidity and mortality and Tanzania is not an exception $[4,6]$.

Despite the current epidemiological knowledge of childhood undernutrition, the challenge of its prevention in most parts of Tanzania remains a significant public health problem [7-9].

UNICEF reports a wide variability of the prevalence of childhood undernutrition in Tanzania across regions and socio-economic groups. At the national level, 38 percent of children underfive years of age are stunted, 22 percent are underweight, 3 percent are wasted and 72 percent are anaemic [2]. These are significantly high percentages nessecitating urgent and effective strategies in addressing this scourge for socieconomic development of Tanzania.

Currently, interventions addressing this problem largely reflect western style medical care, with emphasis placed on reducing mortality and selected preventative aspects confined mainly to vaccinations, food fortifications, child feeding (nutrition rehabilitation) and micronutrient supplementations. In contrast, environmental and 
social factors, which underpin the root causes of the condition are receiving minimal attention [10-12]. This traditional approach to nutrition problems focusing on the individual and the immediate (often medical) problem without giving much consideration to the search of the underlying causes of the problem indicates the need for comprehensive and effective public health strategies to prevent childhood undernutrition in Tanzania.

This paper reviews the literature on effective strategies that are outside the healthcare sector and are critical in addressing childhood undernutrition in Tanzania and may be transferable to other developing countries.

\section{METHODS}

A systematic search of literature was conducted to identify the current knowledge regarding a comprehensive approach towards preventing childhood undernutrition which would be applicable to Tanzania [13].

The following databases were searched: CINAHIL, ELDIS, MEDLINE, POPLINE MEDLINE (Ovid), Scopus, WHO (Statistical Information System) and ProQuest. Hand searches were also conducted to identify the gray literature including searching for publications and reports from the Ministry of Health in Tanzania. Publications during the period of 10 years from 2001 to 2011 and information related to the prevention of undernutrition in children in developing countries especially in Tanzania were included. On the other hand, publications related to developed countries or clinical aspects of undernutrition were not included.

The following search terms were used in combination and/or singly: malnutrition, undernutrition, children, public health strategy(ies), developing countries, Tanzania. References cited in relevant publications were also reviewed. Because of the methodological complexity and limited number of articles providing high level of evidence, narrative as opposed to systematic review has been conducted.

\section{RESULTS}

A total of 58 out of 387 identified articles met the inclusion criteria. Six major emerging themes were identified through recurrence in literature as well using our experiences and knowledge of public health related to this subject. Identified themes included empowerment strategy, advocacy, addressing poverty, behavioural change communication strategy, multi-sectoral collaboration and a comprehensive approach strategy. Details of these are described below:

\section{i. EMPOWERMENT STRATEGY}

With the convergence of childhood undernutrition social risk factors into the overarching construct of powerlessness, how to address powerlessness in tackling childhood undernutrition becomes a necessity. Empowerment has been recognised as an important strategy of addressing childhood undernutrition as it brings back power 
to the marginalized people by improving people's participation in their own development in a meaningful way. It also influences change from the grassroots or local levels and it increases individual and community control over various program that impact on their health [14-15]. Empowerment has also been described as one of the pillars of Primary Health Care (PHC) worldwide [15-16]. As such, empowerment can be in many forms including health [17, 18], education [19], economic, political and gender empowerment $[15,20]$. Each of these has its own strengths in addressing childhood undernutrition issues $[15,19]$. For example education empowerment has been described as a strategy which enables communities to value and analyse their own experience and create their own plans of action to meet the identified needs. On the hand, gender empowerment is based on feminist perspective which addresses gender imbalance and class related differences in power [20]. Health education and the acquisition of health literacy provides an understanding and influences not only individual lifestyle decisions, but also raises awareness of the determinants of health, and encourages individual and collective actions which may lead to a modification of these determinants [21].

\section{Community empowerment and childhood undernutrition}

Community empowerment addresses the social, cultural, political and economic determinants that underpin undernutrition, and seeks to build partnerships with other relevant sectors in finding solutions $[15,18,21]$. It has been explained that community empowerment may address health issues within the context of health promotion by using community development continuum model that progresses across the levels of empowerment [ 17, 20]. It begins with personal empowerment, followed by creating a sense of community through the development of small mutual support groups, community organizations, issue identification and campaigns, then participation in organizations and coalitions. These lead to collective political and social actions and the gaining of control over resources, all of which ultimately are associated with improved nutritional status $[15,17]$.

\section{Women empowerment and the problem of childhood undernutrition}

It is necessary to empower women in addressing childhood undernutrition due to the fact that women throughout the world have the major responsibility for their families' nutrition [22]. Developments that improve women's position in society are likely to improve nutrition overall. Equally, any activities aimed at preventing childhood undernutrition depend substantially on women's activities and therefore the need for women empowerment [22, 23]. Because of reasons including oppression and subordination, women in most developing countries (with Tanzania included) are generally the poorest in the society and yet they are the major care takers of the families. For these reasons, women empowerment is necessary in Tanzania to address issues including childhood undernutrition. Women's empowerment resulting in their improved socio-economic status often leads to women's changing in social norms and attitudes which may lead to improved nutritional and dietary related behaviours of the entire families [22]. These changes resulting from women empowerment within the household can facilitate decision making and improve child nutrition status [6]. Low socioeconomic status of women impairs their ability to make decisions about investments in their children's health, nutrition, and education and prevents them

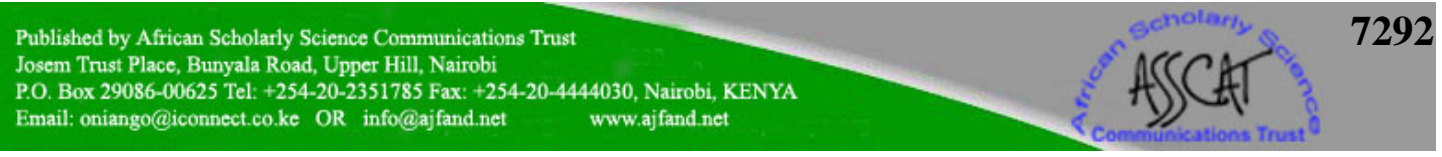


from gaining access to the services they need to protect their own health as well as their children's health and survival [6]. It has been described that women with higher socioeconomic status have improved chances of living in better conditions, resulting in healthier outcomes $[24,25]$. The poor nutritional and social status of women in Tanzania means that poverty and childhood undernutrition becomes inheritable, whereby chronically malnourished mothers lacking access to adequate prenatal, delivery and postnatal care are at increased risk of delivering undernourished babies, who in turn are at a greater risk of poor growth and development, have higher rates of infections, and have a greater probability of dying from the effects of infections and undernutrition compared to children of well nourished mothers [12, 25].

Addressing these issues require empowerment of women through empowerment continuum model as outlined by Nutbeam and Harris [26].

- Community workers and health professionals can work with people in a community in a way that increases their self confidence and their capacity to act in identifying their own solution to nutrition problems,

- Working with existing community structures in urban and rural areas e.g. women groups, youth groups, religious groups and other necessary available structures including traditional healers, and

- Mobilizing community groups and leaders to recognize and demand good nutrition for women and young children in particular and expanding their social network,

As the community becomes more empowered it will work on specific issues, link with other groups to take wider actions and eventually engage in collective social actions which can change the situation of childhood undernutrition at a very local level [20, 25].

If well implemented, community empowerment is an effective approach to addressing childhood undernutrition problem in Tanzania. Evidence of this model can be depicted from the Tamil Nadu nutrition project in India where a grassroots' initiative led to improved nutritional outcomes for targeted communities. The initiative aimed to improve women's awareness of nutritional needs of children in 9000 villages. A group of twenty women interested in health issues were hired in each village as part time community workers accountable to the community. The project encouraged families to adopt a limited number of simple practices to improve the nutrition and health status of children. The objective was to change intra-family food distribution so that children's needs were served first. Other strategies included educating women and raising their awareness on the importance of colostrum and breast feeding, timely introduction of solid foods to supplement breast milk, home management of diarrheal illnesses, immunization and improved environmental hygiene. Due to a better handling of health and nutritional needs of children the project resulted into a decline of severe undernutrition by one third in a short period of time [24].

\section{The relevance and implications of community empowerment to the childhood undernutrition}

Community empowerment is widely accepted as an effective health promotion strategy. The Ottawa Charter for Health Promotion identifies strengthening of community action through empowerment as an important health promotion strategy 


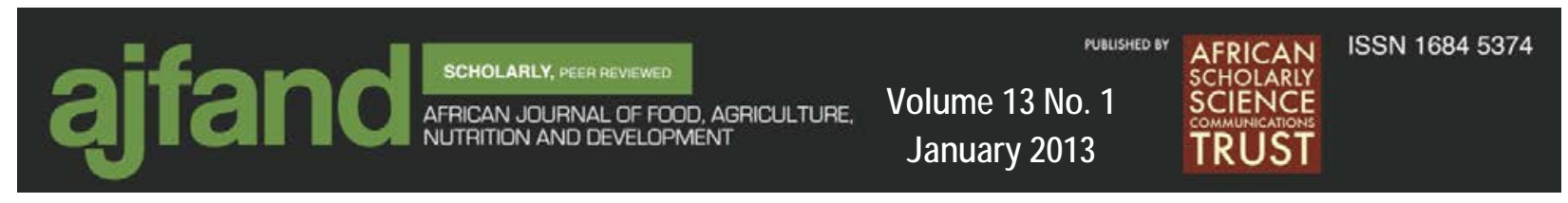

[17]. The Alma Ata Declaration of Primary Health Care outlines community participation as one of the core elements to any health promotion initiatives [16, 27]. Empowerment is important in public health as it improves people's participation and increases individual and community control over various programs that impact on their health. Empowerment also improves a sense of local ownership and collaboration and therefore ensures sustainability of developed programs [18]. Empowerment is concerned with increasing power and willingness of marginalized people and influences their health in a positive way by reducing health inequities and increasing access to services.

\section{ii. ADVOCACY}

Advocacy has been identified as one of the strategies to addressing childhood undernutrition. It has also emerged in different disciplines that advocacy for public health nutrition aims at influencing key decision makers and raising public awareness in order to fuel a demand for nutrition-enhancing policies and actions [28-30]. Advocacy for public health nutrition is based on clear understanding of the factors that affect the nutrition of populations in various contexts. For example, Wande and Ottesen [31] and Tontisirin and Bhattacharjee [32] argue that two streams of reasoning underlie advocacy including actions on the basis of obligations related to nutrition rights, and nutrition-promoting actions that aim at showing their economic benefits and economic cost of non-implementation.

Advocacy has also been recognised as one of three major strategies for achieving health promotion goals, with others mentioned as enablement and mediation [17, 18, 26]. The World Health Organisation describes advocacy for health as a combination of individual and social actions designed to gain political commitment, policy support, social acceptance and systems support for a particular health goal or program [17, 24].' Advocacy may be explained in terms of the activities it encompasses: for example, the representation of under-privileged groups, such as those who are disadvantaged or sick, with the aim of promoting their rights and/or redressing imbalances in power. This has been characterized as 'case' advocacy [33, 34]. Advocacy is also seen as a lobbying activity within public health. This approach acknowledges that barriers to health can lie beyond the control of individuals and that structural factors need to be addressed if health inequalities are to be reduced [18, 35]. This has been characterised as 'cause' advocacy [33]. Both types can be categorised as representational advocacy. However, health promotion recognises the values of democratic participation, community development and empowerment, wherein disadvantaged individuals or groups are enabled to represent themselves and lobby for their own health needs. The role of advocacy here is best categorised as facilitative rather than representational, providing individuals and communities with the skills to tackle and redress inequalities in health.

\section{How advocacy addresses the problem of child undernutrition}

Advocacy for public nutrition aims to influence key decision makers and raise the consciousness of the public in order to fuel a demand for nutrition-enhancing policies and actions. Advocacy for public health nutrition is based on clear understanding of

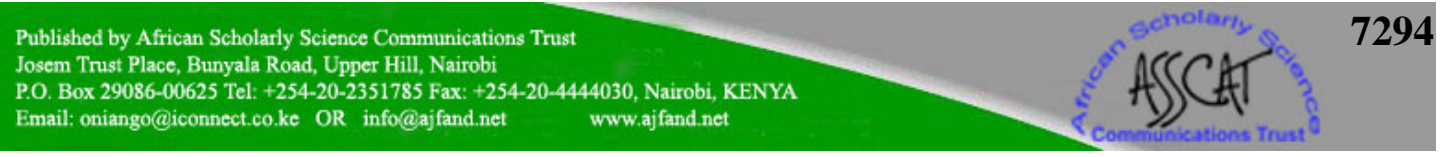




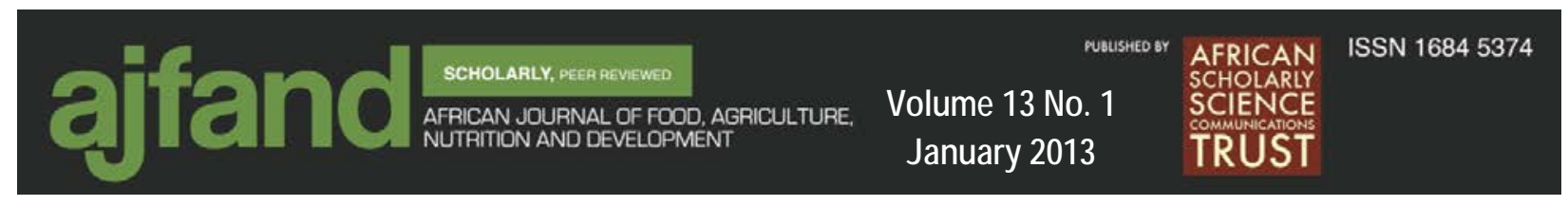

the factors that affect the nutrition of populations in various contexts and is designed to gain political commitment or support for a particular health goal [29, 36].

It has been argued that, problems of childhood undernutrition still persists because nutrition programs have been left behind compared to other investments and have been considered as an outcome rather than an input to development [12]. This is also due to structural limitations to health as the government gives less priority to the nutrition sector when compared to other sectors which are believed to contribute directly to the economy of the country [29, 37]. Consistent with the Ottawa Charter of Health Promotion [17], it is important to include advocacy as a means to act on upstream level to influence the government to formulate healthy public policy to address the childhood undernutrition problem and to prioritise nutrition issues as a developmental necessity $[17,18]$. As mentioned previously, the continuing presence of gender inequalities, food insecurity and poverty lie beyond the control of individuals, and that structural factors need to be addressed through advocacy if health inequalities and childhood undernutrition were to be reduced.

In Tanzania advocacy for nutrition is also required to raise the profile of nutrition in general; achieve greater cohesion between interventions addressing chronic and acute causes of childhood undernutrition; win broader recognition of the various causes of undernutrition (not just related to food); revise and change health policies that support more equitable health services; ensure that social, cultural and gender-related causes are consistently addressed; and make certain that changes in giving local farmers incentives to enable them to produce enough food for their family and for the cash needs. Advocacy must be sustained and systematically communicated to all stakeholders, including both government and non-government organisations such as the United Nations and other funding agencies [2, 22].

\section{The relevance and implications of advocacy to public health nutrition}

Two main goals underpin health advocacy: that of protecting people who are vulnerable or discriminated against; and that of empowering people who need a stronger voice by enabling them to express their needs and make their own decisions [30].

The World Health Organisation acknowledges that advocacy is one of the enablers of the creation of healthy public policies. These may then include policies that address the problem of childhood undernutrition. As mentioned previously, advocacy can act to put pressure in the upstream level (policy development) to create supportive environment and help people to live healthy life [17, 30]. The creation of supportive environment is important in any health promotion activity because it is common knowledge that health determinants, including those for childhood undernutrition are beyond individual control. Healthy public policy is an integral part of health promotion and it helps in shaping and regulating social and physical environment which impact on health. Without the support of healthy public policy, other health promotion actions are likely to be of limited value [17, 27]. 


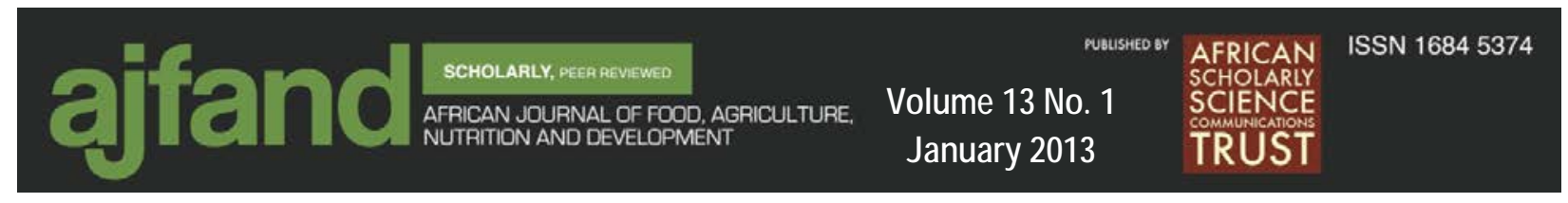

Several policies and strategies have been suggested to combat undernutrition and to achieve an acceptable nutritional status [11,38], including

- Income related policies: The income-related policies intended to increase the purchasing power of the lower income groups, allowing them to compete more fairly in the market for the acquisition of food: this also was intended to create a pull on the food demand side that would later provide an incentive for agricultural production

- Agriculture reform and accelerated rural development: focused on efforts to increase agricultural output (supply side) by giving the people control over their food-producing resources and by helping them technically to achieve the production goals set. Rural development, linked to urban and rural employment generation policies

- Employment generation: attempted to create new income opportunities for the people. An increase in the purchasing power for the poor was attempted knowing that food has a high elasticity of demand at those income levels

- Government democratisation and decentralisation: government democratisation and decentralisation policies had an impact on both food supply and demand, as well as on the prevention of food losses and malnutrition.

Advocacy may also have a capacity building function, providing support for disadvantaged individuals and/or communities to gain control over and improve their own health [14]. The aim of public health is to improve the health of communities through employing all three: (i) providing advocacy for healthy public policies and supportive environments; (ii) mediating between different interests in society to benefit health; and (iii) enabling communities and individuals to achieve their full potential [33]. Under these backgrounds, advocacy is inevitable if we need to combat the problem of child undernutrition in Tanzania.

\section{iii. POVERTY AND CHILDHOOD UNDERNUTRITION}

Several studies have highlighted poverty as a significantly strong predictor of childhood undernutrition in most of developing countries. It has also been pointed out that poverty can lead to low levels of parental education, poor housing, poor access to basic and social needs including water and sanitation [39-41]. As such poverty which leads to the scarcity of resources, can result in low purchasing power of adequate and nutritious food leading to both macro and micronutrient deficiencies and overall undernutrition.

Similar to other developing countries, in Tanzania poverty is a strong and important predictor of childhood undernutrition. In order to address this scourge, poverty must therefore be addressed first. Recent studies have demonstrated the pervasiveness of effects of poverty on childhood undernutrition. For example, poor households are unable to achieve sufficient food security and other social needs. They have inadequate resources to maintain good health on a sustainable basis as they are unable to access necessities in life including health care needs [37, 42-44]. The poor status of most households in Tanzania has commonly been regarded as the basic root 


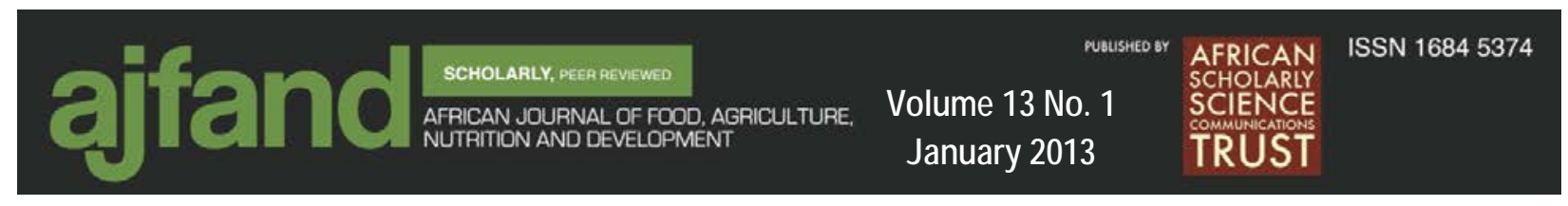

predictor of childhood undernutrition. As such, efforts to improve childhood undernutrition in Tanzania will be enhanced when poverty is also addressed.

\section{iv. BEHAVIOURAL CHANGE COMMUNICATION STRATEGY}

Behaviour change communication strategy is one of important strategies in preventing childhood undernutrition. It encompasses education, mass media campaigns and counseling [45]. Behaviour change communication strategies targeting mothers, caregivers, family members and decision makers should be central as strategies to addressing the nutrition of infants and young children [38, 46-49].

It has been pointed out that care giving behaviours that contribute to good nutritional status of children aged up to five years include: early initiation of breastfeeding, exclusive breastfeeding for the first six months of life, appropriate and timely introduction of complementary foods, good feeding practices, immunization, the proper management of childhood illnesses including acute respiratory infections (ARI) and diarrheal illnesses good hygiene and birth spacing [1,50]. It has also been noted that behavioural change strategy is essential in addressing inappropriate cultural practices that affect childhood nutritional status [51, 52]. Behavioural change should promote a wide range of practices recommended for specific ages in a culturally appropriate and timely way, targeting not just those who practice the behaviours but those who influence the behaviours in a household and the community. For effective outcomes, it is necessary to combine behaviour change communication strategies with other strategies such as community involvement, community empowerment and creating supportive environment in addressing childhood undernutrition effective approach to malnutrition problem [3, 4].

\section{v. MULTISECTORAL COLLABORATION}

It has been demonstrated from above that the nutrition of populations is determined not only by health sector strategies alone but by social and economic factors and hence by the nutrition policies and actions beyond the boundaries of the health sector [21]. Consistent with the Alma Ata Declaration and the Ottawa Charter [16,17] it is important for the health sector to work in collaboration with other sectors to raise awareness of the co-benefits of acting together for people-centered policies that promote health and improve childhood undernutrition [20, 30, 53, 54]. We have also demonstrated the link between childhood undernutrition and poverty issues including the lack of or low literacy level that leads women to inadequately feeding their babies, having poor access to health, having low agricultural production, living in unsanitary environments, women experiencing heavy workload and resulting in low income [11, 55]. It is, therefore, plausible to argue that improvements in nutritional status can only be achieved with interventions across different sectors. Programs aimed at reducing women's workload, improving food security and increasing income have had an impact on nutrition. For the Tanzanian context, it would be necessary for the government to launch a 'whole of government' initiative in addressing childhood undernutrition and therefore the health sector to work very closely with other pertinent sectors including agriculture, community development, the Prime Minister's 
Office, Education and Finance to examine how different parties' policies could help achieve improved childhood nutrition. Recently, this cross sector approach has been termed 'Health in All Policies' whereby multi-sectoral collaboration integrate the efforts from different parties within and outside health sectors, combining different approaches to improve health and ensure representations of a problem from different aspects, and therefore generates diverse solutions targeting different aspects of a health problem.

\section{vi. A COMPREHENSIVE APPROACH TO CHILDHOOD UNDERNUTRITION}

The concept of comprehensive approach to child undernutrition basically was derived from the fundamental concept of comprehensive Primary Health Care in the Alma Ata Declaration and explicitly outlined strategies which would respond appropriately to the current health and nutrition needs, including addressing broad social determinants of poor health and nutrition $[16,56]$. A comprehensive approach is a holistic strategy which acknowledges the role of social determinants in influencing the nutritional status of a child. A range of studies provide information on the impact of disease specific interventions on children with severe undernutrition. Children with severe malnutrition often present with multiple and complex problems that necessitate the need for comprehensive approach which recognises the complexity of the problem [9, $10,57,58]$. Recent studies have shown that the selective model (medical model) does not acknowledge the role of social equity and social justice for the recipients of technologically driven medical interventions [59-61]. The reality of this model (in the Tanzanian context) is that vertical programs are centered in urban hospitals and health care facilities. Without the participation of communities, there are limited avenues for change despite the existence of growth monitoring programs, vaccinations and supplementation programs. This indicates the need for a comprehensive approach and not disease specific approach in addressing childhood undernutrition. A comprehensive approach acknowledges the holistic understanding of child undernutrition problem and its social determinants especially at grassroot and local levels.

\section{How a comprehensive approach addresses the problem of childhood undernutrition}

Because of the multifaceted aspects of child undernutrition, a comprehensive approach which incorporates preventive, health promotion activities and addresses the social, economical and environmental determinants of childhood undernutrition is described as an effective strategy in most of the reviewed literature [1, 16, 30, 56]. The Alma-Ata Declaration explicitly outlines comprehensive primary health care as an approach that addresses the social, economic and political causes of poor health and nutrition [16]. The problem of childhood undernutrition is complex, and therefore it cannot be addressed by standalone medical interventions (selective model). It needs a more broad approach which incorporates other determinants such as social, economic and environmental determinants [27, 58]. It has been alluded that the problem of childhood undernutrition in Tanzania has persisted due to the fact that interventions addressing this scourge largely reflect western style medical care, with emphasis placed on reducing mortality and preventive aspects confined mainly to

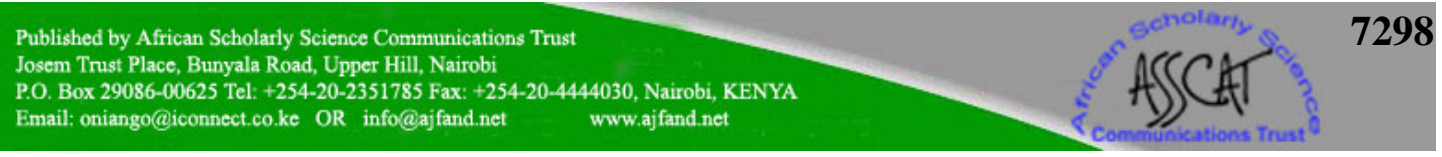


immunization, food fortification, child feeding (nutrition rehabilitation), supplements and vaccinations. In contrast, broad environmental and social factors which underpin the root causes of the condition are receiving minimal attention [10]. This traditional approach to the nutrition problems focusing on the individual and his immediate (often medical) problem, without giving much consideration to the search of the underlying causes of the problem indicates the need for comprehensive approach to address the problem of child undernutrition in Tanzania.

\section{The relevance and implications of comprehensive approach to the public health}

New public health recognises that ill health arises from a combination of biological, social, economic, and environmental factors [18]. Action to improve ill health will likewise need to be directed at these broad determinants [27]. Children with severe undernutrition often present with multiple problems that necessitate the need for comprehensive approach which recognizes the underlying and basic causes of malnutrition. The selective model (disease specific intervention), does not acknowledge the role of other factors which contribute to the problem of child undernutrition [62]. It is clearly stated in the Ottawa charter [17,63] as well as in the Jakarta declaration that "the prerequisites for health are peace, shelter, education, social security, social relations, food, income, the empowerment of women, a stable eco-system, sustainable resource use, social justice, respect for human rights, and equity. Above all, poverty is the greatest threat to health.” Based on these assertions, it is clear that food, women empowerment and poverty are among necessary prerequisites for health and they have strong outcome in nutritional status of children [63]. Addressing these factors requires an inclusive approach to health promotion, which can change the practices of social systems that have widespread detrimental effects on health rather than solely changing the habits of individuals. The new public health works under (3 P's) including promoting health, preventing disease and population focus. From this view a comprehensive approach is necessary in combining these aspects by dealing with prevention rather than treatment, focusing on population rather than individual and promoting health rather than leaving health professionals alone to take control of health issues [ 18, 21].

\section{DISCUSSION}

It is clear that childhood undernutrition remains the major public health problem of the $21^{\text {st }}$ Century and a significant contributor to childhood morbidity and mortality in Tanzania and other developing countries. In Tanzania, this problem has been described as responsible for one third of deaths in children under 5 years, making it a significant cause of the under five mortality in the country [6]. The prevalence of childhood undernutrition varies widely across regions and socio-economic groups but overall, the vast majority of the population is affected. Although it is plausible to agree with the medical professionals and consider insufficient nutrients to be the cause of childhood undernutrition, far more than medical causes are predictors of this scourge. The causes are complex and include a complex combinations of social, cultural, economic and environmental factors rooted with poverty [1, 64]. 
This review provides the next level strategies to combat the problem of childhood undernutrition. These strategies are not explicit, but complementary to current strategies which largely reflect a western style medical care model; and place great emphasis in reducing mortality and preventive aspects confined to biological and curative interventions. It has to be acknowledged that, in contrast to medical interventions which are significant strategies in addressing the childhood undernutrition in Tanzania, environmental and social factors which underpin the root predictor of the condition have received minimal attention and this needs to be addressed [10, 62]. The traditional approach to addressing the childhood undernutrition problem mainly focusing on the individual and her immediate (often medical) problem, without giving much consideration to the search of the underlying causes of the problem indicates the need for effective new public health strategies to prevent child under nutrition in Tanzania.

Evidence indicated clearly the need to consider comprehensive approach with multiple strategies which not only address the problem of child undernutrition, but also take into account the social, cultural, economic and environmental context in which a child lives [60, 61, 65].

\section{CONCLUSION}

The new public health approach recognises that ill health arises from a combination of biological, social, economic, and environmental factors. Actions to improve ill health will likewise need to be directed at these broad determinants [27]. It is, therefore, plausible to conclude that childhood undernutrition is still the most important public health problem in Tanzania and its effective reduction and prevention depends on integrated interventions that can reduce poverty and improve the quality of life of unprivileged families and communities. In light of the emerging issues in this review, it is high time for Tanzania to act on preventing childhood undernutrition as a social justice and an equity issue. The right of children to live, grow and become healthy adults is a necessity and needs to addressed effectively. The high prevalence of childhood undernutrition prevailing in the country is not acceptable and it requires the new public health approach which incorporates prevention, promotion and population aspects, by addressing the wider determinants in combination with strategies including empowerment, advocacy, multilevel and multisectoral and a comprehensive approach. As the childhood undernutrition is multidimensional and complex, more than health sectors are needed in addressing it. Community empowerment has to be at the center of health promotion actions so as to enable people to identify their needs and generate their own solutions in a sustainable way [15]. It should also be remembered that some of the determinants of health lie beyond the control of individuals, example poverty, poor nutrition policies, food insecurity and gender inequalities. These may lead to structural limitation in achieving health and good nutritional status, and as such these determinants need to be addressed through advocacy if health inequalities and childhood undernutrition are to be reduced in Tanzania. 


\section{REFERENCES}

1. De Onis M, Frongilo EA and M BlÖssner Is malnutrition declining? An analysis of changes in levels of child malnutrition since 1980. Bulletin of the World Health Organization 2000; 78 (10): 1222-1233.

2. UNICEF. United Nations Children Fund. Malnutrition, the silent emergency. availabale at http//www.unicefusa.org/malnutrition. Accessed 28 November 2011.

3. UNICEF. United Nations Children Fund. Tracking Progress on Child and Maternal Nutrition: A survival and development priority. UNICEF, New York, 2009.

4. Martines J, Paul VK, Bhutta ZA, Koblinsky M, Soucat A, Walker N, Bahl R, Fogstad $\mathbf{H}$ and A Costello Neonatal survival: a call for action. The Lancet, 2005; 365:1189-1197.

5. INDEPTH. International Development Research Centre. Demographic Surveillance Systems for Assessing Populations and Their Health in Developing Countries. Population, Health and Survival in INDEPTH Sites. Ottawa, 2001.

6. $\quad$ Alderman H, Appleton S, Haddad L, Song L and Y Yohannes Reducing Child Malnutrition: How Far Does Income Growth Take Us? Washington, DC: World Bank. 2000.

7. Mrisho M, Armstrong Schellenberga J, Mushi AK, Obrist B, Mshinda H, Tanner $\mathbf{T}$ and $\mathbf{D}$ Schellenberg Understanding home-based neonatal care practice in rural southern Tanzania. Transactions of the Royal Society of Tropical Medicine and Hygiene, 2008; 102 (7): 669-678.

8. Shirima R, Greiner T, Kylberg E and M Gebre-Medhin Exclusive breastfeeding is rarely practised in rural and urban Morogoro, Tanzania. Public Health Nutrition, 2001; 4: 147-154.

9. Victora CG, Smith PG and JP Vaughan Evidence for protection by breastfeeding against infant deaths from infectious diseases in Brazil. Lancet, 1987; 2: 319-322.

10. Ehiri JE and JM Prowse Child health promotion in developing countries: the case of integration of environmental and social interventions Health Policy and Planning, 2000; 14 1: 1-8.

11. Mturi A and S Curtis The determinants of infant and child mortality in Tanzania. Health Policy and Planning, 2005; 10 4: 384-394. 
12. Armstrong M, Nathan R, Abdulla S, Mukasa $\mathbf{O}$ and TJ Marchant Risk factors for child mortality in rural Tanzania. Tropical Medicine \& International Health, 2002; 7 \{6\}: 506-511.

13. Saks MJ Researching Health: Qualitative, Quantitative and Mixed Methods. Sage Publications, London, 2007.

14. McMurray A Community health and wellness: A sociological approach, 3rd edn, Elsevier, Australia, 2007.

15. Mwanri L, Hiruy $\mathbf{K}$ and $\mathbf{J}$ Masika Empowerment as a tool for a healthy resettlement: a case of new African settlers in South Australia," International Jounral of Migration, health_and Social Care, 2012; 8( 2): 86-98.

16 Alma Ata Declaration. International Conference on Primary Health Care, meeting in Alma-Ata, USSR, 6-12 September, 1978.

17. World Health Organisation. The Ottawa Charter for Health Promotion. WHO: Geneva, 1986.

18. Baum F The New Public Health, 3rd edn,Oxford University Press, South Melbourne. 2008

19. Wallerstein $\mathbf{N}$ and B Edwards Empowerment education: Freire's ideas adapted to health education. Health Education Quartery, 1988; 15 (4): 379394.

20. Laverack G Public Health: Power, empowerment and professional practice, 2nd edn, Palgrave Macmillan, New York. 2009.

21. WHO. World Health Report. Primary Health Care: Now more than ever. 2008 available at

http://www.who.int/healthpromotion/conferences/7gchp/track4/en/index.html. Accessed on $28^{\text {th }}$ December 2011.

22. United Nations. Millennium Development Goal.Promoting gender equality and women empowerment. Geneva,2000. available at http://www.beta.undp.org/undp/en/home/mdgoverview.html Accessed on $28^{\text {th }}$ December 2011.

23. Larrea C and I Kawachi Does economic inequality affect child malnutrition? The case of Ecuador. Social Science \& Medicine, 2000; 60 1: 165-178.

24. Government of Tamil Nadu India.National Informatics Centre. Available at http://www.tn.gov.in/citizen/tinp.htm. Accessed on $23^{\text {rd }}$ December 2011.

25. Fotso JC and BK Defo Socioeconomic inequalities in early childhood malnutrition and morbidity: modification of the household-level effects by the community SES'. Health and Place, 2005;11 3: 205-225. 
26. Nutbeam D and E Harris Theory in a nutshell: A practical guide to health promotion theories, 2nd edn, McGraw-Hill, Australia, 2004.

27. Talbot $\mathbf{L}$ and Verrinder $\mathbf{G}$ Promoting health: the primary health care approach, 4th edn. Elsevier, Sydney, 2010.

28. Pongou R, Ezzati $\mathbf{M}$ and JA Salomon Household and community socioeconomic and environmental determinants of child nutritional status in Cameroon. BioMedical Central Public Health, 2006; 6 98: 2458-6.

29. Black R Maternal and Child Undernutrition: Global and Regional Exposure and Health Consequences. The Lancet, 2008; 371 (9608): 243-60.

30. Keleher $\mathbf{H}$ and $\mathbf{C}$ MacDougall Understanding health: A determinants approach, 2nd edn. Oxford University press, Australia, 2009.

31. Wandel M and G Ottesen Women's Work in Agriculture and Child Nutrition in Tanzania. Journal of Tropical Pediatrics, 2000; 38( 5): 252-255.

32. Tontisirin $\mathbf{K}$ and $\mathbf{L}$ Bhattacharjee Community based approaches to prevent and control malnutrition. Asia Pacific Journal of Clinical Nutrition, 2008;17 (1): 106-110.

33. Egger G, Spark $\mathbf{R}$ and $\mathbf{R}$ Donovan Health Promotion Strategies and Methods, 2nd edn, McGraw-Hill, Australia, 2005.

34. Pat $\mathbf{P}$ and $\mathbf{C}$ Roy Tackling the drivers of child undernutrition in developing countries: what works and how should interventions be designed? Public Health Nutrition, 2011; 14 (4): 688-693.

35. Wilkinson $\mathbf{R}$ and $\mathbf{M}$ Marmot Social Determinants of Health. The Solid Facts. $2^{\text {nd }}$ edn. World Health Organization, Copenhagen; 2005.

36. Saul M, Bruce $\mathbf{C}$ and $\mathbf{U}$ Ricardo Maternal and Child Undernutrition: Effective international action against undernutrition: why has it proven so difficult and what can be done to accelerate progress. The Lancet, 2008; 371 (9682): 608-21.

37. Peterson K Viewpoint: childhood undernutrition: a failing global priority. Journal of Public Health Policy, 2009; 30 (4): 455-64.

38. White H Tackling childhood undernutrition. The Lancet, 2008; 371 (9612): 539-41.

39. Smith LC, Ruel MT and A Ndiaye Why is child malnutrition lower in urban than in rural areas? Evidence from 36 developing countries. World Development, 2005; 33 (6): 1285-1305. 
40. Wolfe B and J Behrman Determinants of child mortality, health and nutrition in a developing country. Journal of Development Economy, 2002; 11 (2): 163-193.

41. Tharakan CT and CM Suchindran Determinants of child malnutrition - An intervention model for Botswana. Nutritional Research, 2000; 19 (2): 843860.

42. Maletnlema TN A Tanzanian perspective on the nutrition transition and its implications for health. Public Health Nutrition, 2002; 5 (1): 163-8.

43. Fotso JC Urban-rural differentials in child malnutrition: Trends and socioeconomic correlates in sub-Saharan Africa. Health and Place, 2007; 13 (5): 205-223.

44. Hong $\mathbf{R}$ Effect of economic inequality on chronic childhood undernutrition in Ghana. Public Health Nutrition, 2006; 10 (4): 371-378.

45. Campbell MK, DeVellis BM, Strecher VJ, Ammerman AS, DeVellis RF and RS Sandler Improving Dietary Behaviour : the effectiveness of Tailored messages in Primary Health Care Settings. American Journal fo Public Health, 1994; 84 (5): 783-787.

46. Favin $\mathbf{M}$ and $\mathbf{M}$ Griffiths Communication for Behavior Change in Nutrition Projects, 2000.World Bank, Washington DC; 1999.

47. Desai $\mathbf{S}$ and $\mathbf{S}$ Alva Maternal education and child health: is there a strong causal relationship? British Medical Journal, 2003; 35 (2): 71-81.

48. Mabilia M Beliefs and practices in infant feeding among the Wagogo of Chigongwe (Dodoma rural district) Tanzania. Ecology of Food and Nutrition, 2003; 35 (3): 209-217.

49. Ruel MT, Menon P, Habicht J, Loechl C, Gilles Bergeron G, Gretel Pelto G and B Hankebo Age-based preventive targeting of food assistance and behaviour change and communication for reduction of childhood undernutrition in Haiti. The Lancet, 2008; 371 (9612): 588 - 595.

50. Kulwa K, Kinabo $\mathbf{J}$ and B Modest Constraints on good child-care practices and nutritional status in urban Dar-es-Salaam, Tanzania. Food and Nutrition Bulletin, 2006; 27 (3): 236-244.

51. Bicego G and JT Boerma Maternal education and child survival: a comparative study data from 17 countries. Social Science and Medicine, 2003; 36 (9): 1207-1227.

52. Chilimo $\mathbf{W}$ and $\mathbf{J}$ Nawe The role of nutritional information in addressing under-five child malnutrition in Tanzania. University of Dar es Salaam Library Journal, 2003; 5 (2): 82-92. 


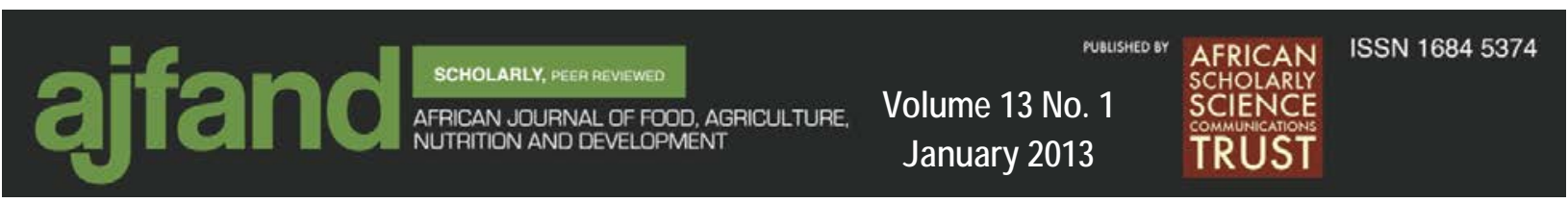

53. Claeson $\mathbf{M}$ and $\mathbf{J}$ Waldman The evolution of child health programmes in developing countries: from targeting diseases to targeting people. Bull World Health Organ. 2000; 78 (10): 1234-1245.

54. Tonia M, Issakha D, Ndiaye Biram $\mathbf{N}$ and $\mathbf{R}$ Jean Successful contracting of prevention services: fighting malnutrition in Senegal and Madagascar. Health Policy and Planning, 2000; 14 (4): 382.

55. Lee LF, Rosenzweig $\mathbf{M}$ and $\mathbf{M}$ Pitt The effects of improved nutrition, sanitation, and water quality on child health in high-mortality populations. Journal of Econometrics, 2003; 77 (5): 209-235.

56. Javanparast S, Coveney J and U Saikia Exploring stakeholder's perception on moving towards comprehensive primary health care to address childhood malnutrition in Iran: A qualitative study. BMC Health Service Research, 2009; 36(9): http://www.biomedcentral.com/content/pdf/1472-6963-9-36.pdf. Accessed 2nd December 2011.

57. Honorati $\mathbf{M}$, Armstrong S, Mshinda $\mathbf{H}$ and V Cesar Impact of Integrated Management of Childhood Illness on Inequalities in Child Health in Rural Tanzania. Health Policy and Planning, 2005; 20 (4): 77-84.

58. Magnussen L, Ehiri $\mathbf{J}$ and $\mathbf{P}$ Jolly Comprehensive Versus Selective Primary Health Care: Lessons For Global Health Policy. Health Affairs, 2004; 23 (3): 167-176.

59. Obimbo EM Selective or Comprehensive: Which way to go? East African Medical Journal, 2003. 80 2: http://www.bioline.org.br/ Accessed $28^{\text {th }}$ December 2011.

60. Wass A Promoting health: The Primary Health Care Approach. 2nd edn, Harcourt, Australia, 2002.

61. Ian D, Pelletier $\mathbf{M}$, David $\mathbf{P}$ and $\mathbf{P}$ Andersen Maternal and child undernutrition: effective action at national level. The Lancet, 2008; 371 (9611): 510-26.

62. Victora CG, Adair LC, Fall P, Hallal R, Martorell L, Richter $\mathbf{H}$ and S Singh Maternal and child undernutrition: consequences for adult health and human capital. The Lancet, 2008; 371: 340-357.

63. World Health Organisation. Jakarta declaration on leading health promotion into the 21st century. WHO, Jakarta. 1997.

64. Wandel $\mathbf{M}$ and G Ottesen Women's Work in Agriculture and Child Nutrition in Tanzania. Journal of Tropical Pediatrics, 2000; 38 (5): 252-255.

65. Werner D and D Sanders Question the solution: The politics of Primary Health Care and Child Survival, Health rights, USA, 1997. 


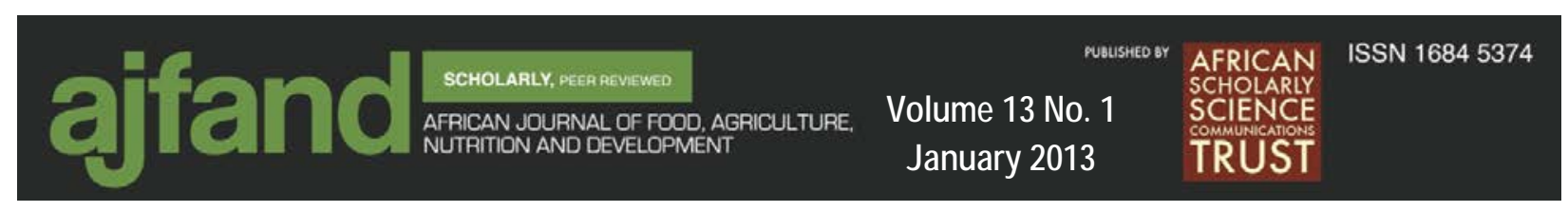

66. Caulfield L, Richard SA and RE Black Undernutrition as an underlying cause of Malaria morbidity and mortality in children less than five years old. American Journal of Tropical Medicine and Hygiene, 2004; 71 (2): s55-s63. 